\title{
Perioperative cardioprotection
}

\section{May KM Leung and Michael G Irwin*}

\author{
Address: Department of Anaesthesiology, University of Hong Kong / Queen Mary Hospital, Hong Kong SAR, China \\ * Corresponding author: Michael G Irwin (mgirwin@hku.hk) \\ Fl000Prime Reports 2013, 5:6 (doi:10.12703/P5-7) \\ This is an open-access article distributed under the terms of the Creative Commons Attribution-Non Commercial License \\ (http://creativecommons.org/licenses/by-nc/3.0/legalcode), which permits unrestricted use, distribution, and reproduction in any medium, \\ provided the original work is properly cited. You may not use this work for commercial purposes. \\ The electronic version of this article is the complete one and can be found at: http://fl000.com/prime/reports/m/5/7
}

\begin{abstract}
Although anaesthesia itself is now very safe, perioperative cardiac complications during non-cardiovascular surgery are a major cause of morbidity and mortality, because of the increasingly high underlying prevalence of cardiovascular disease. Fortunately, although there is no "magic bullet", pharmacological intervention can reduce the risk. In particular, current evidence strongly supports the use of aspirin and statins. Beta blockers may also be beneficial in higher risk groups but need to be titrated to effect, and their use requires careful consideration because of adverse effects in these patients.
\end{abstract}

\section{Introduction}

Despite better awareness of epidemiology and pathophysiology, the worldwide prevalence of cardiovascular disease is increasing. Contemporaneously, medical advances are resulting in more patients with cardiovascular comorbidity presenting for surgery. Although anaesthesia itself is now very safe $[1,2]$, perioperative cardiac complications are a major cause of morbidity and mortality as a consequence of the high underlying prevalence of cardiovascular disease; for example, the American Heart Association (AHA) estimates that more than 2200 Americans die of cardiovascular disease each day, an average of 1 death every 39 seconds [3]. Fortunately, there is evidence that pharmacological intervention can reduce risk. This review will look at the drugs available and their possible mechanisms in modifying the pathophysiology of a perioperative acute myocardial infarction. The roles of other interventions such as prophylactic coronary revascularization, anaesthetic technique and cardiac conditioning are also discussed.

\section{Pathophysiology and risk stratification}

The pathophysiology of perioperative myocardial infarction is more complex than in the non-surgical setting. The metabolic responses to surgical stress and pain alter physiology and trigger a cascade of biochemical events that are prothrombotic. Moreover, myocardial oxygen consumption is raised during the perioperative period, which affects the oxygen supply/demand balance, and intraluminal shear forces in the coronary artery can be increased. This is a "perfect storm" for atheromatous plaque rupture and subsequent coronary artery thrombosis. Many of these vulnerable plaques are asymptomatic preoperatively and may not even be apparent with angiography, as a result of positive remodelling within the vessel $[4,5]$.

Preoperative risk stratification aims to determine who is at risk, optimize medical therapy and modify risk factors. Unnecessary and costly cardiac testing should be avoided if possible, as it can be potentially hazardous and often has no impact on the perioperative management [6]. A number of guidelines and risk scores have been developed to evaluate perioperative cardiac risk. For instance, Lee's Revised Cardiac Risk Index identifies six independent variables that predicted an increased risk for perioperative cardiac complications. These include the following: (1) history of ischaemic heart disease; (2) history of congestive heart failure; (3) history of cerebrovascular disease; (4) diabetes mellitus; (5) chronic renal impairment (creatinine $>2 \mathrm{mg} / \mathrm{dL}$ ); and (6) undergoing suprainguinal vascular, intraperitoneal, or intrathoracic surgery [7]. This risk index is also incorporated into the AHA preoperative cardiac risk evaluation guideline for non-cardiac surgery [8]. 
Surgical coronary revascularization is a major undertaking with significant morbidity and mortality itself. Percutaneous coronary intervention with balloon angioplasty and stenting, while effective for the treatment of angina, does not reduce the risk of perioperative myocardial infarction, probably because it does not treat all the atheromatous plaques present. Paradoxically, percutaneous coronary intervention actually increases the risk of thrombosis by virtue of vessel trauma and stent insertion. Patients will require dual antiplatelet therapy with aspirin and clopidogrel, thereby increasing bleeding during surgery $[9,10]$. This treatment needs to be continued for three months with bare metal and at least a year with drug eluting stents. Since surgery in such patients is often not truly elective (e.g. cancer or vascular surgery) the emphasis has shifted from coronary revascularization to medical therapy in recent years.

Medical therapy is generally focused on improving myocardial oxygen supply-demand balance and coronary plaque stabilization. Data from large registries and clinical trials indicate that drugs that have demonstrated protective cardiovascular properties in the population of patients treated medically may also confer benefits in those treated surgically [6]. In addition to losing the pharmacological benefits of a drug, discontinuation of therapy (either perioperatively or otherwise) may cause a rebound phenomenon. This has been demonstrated with beta-blockers, aspirin, and statins. As a result, these drugs should be continued throughout the perioperative period or discontinued for the minimum period possible.

\section{Risk modulation Aspirin}

Aspirin has been used as an analgesic and antiinflammatory agent since 1897 . Today, however, it is most widely used as an antiplatelet agent. The drug works on the cyclooxygenase enzyme system to irreversibly inhibit platelet aggregation. It takes 5-7 days to produce new platelets after cessation of therapy. In primary coronary prevention, it is probable that the anti-inflammatory properties of aspirin are also extremely important $[11,12]$.

As platelet aggregation predominates during the perioperative period, management of aspirin therapy is imperative. While increased surgical bleeding is generally evident, this is usually not clinically significant and transfusion requirements have been found to be similar, regardless of aspirin uptake [13]. In addition, there is an approximate 2-3 fold increase in subsequent death or myocardial infarction if aspirin is stopped prior to surgery [14]. In patients with coronary stents in situ, it is strongly advised to continue with aspirin, especially in the period when in-stent thrombosis is prevalent and can cause a $5-30 \%$ mortality rate depending on how recently the stent has been inserted [15-19]. Interestingly, this perioperative cardioprotection effect is not apparent with other nonsteroidal anti-inflammatory drugs (NSAIDs) as they have a different mechanism of action [20]. In fact, both NSAIDs and cox-2-specific inhibitors have been associated with an increased risk of perioperative myocardial infarction in certain patients and procedures [21]. It is also important to point out that aspirin protection cannot be substituted by anticoagulant medication (e.g. low molecular weight heparin often used for deep vein thrombosis [DVT] prophylaxis) as they do not inhibit platelet function or decrease inflammation.

\section{Beta blockers}

Beta adrenoreceptor antagonists are a particularly useful class of drugs for the management of cardiac arrhythmias, cardioprotection after myocardial infarction and hypertension. They diminish the effects of epinephrine and other stress hormones and have negative chronotropic and inotropic actions. Beta blockers may also limit activation of inflammatory responses including leukocyte recruitment, metalloproteinase activity, monocyte activation, growth factor release, and inflammatory cytokine responses [22]. They protect the coronary endothelium from damage by shearing forces and turbulent flow, thus reducing atheroma formation and plaque rupture. They reduce myocardial energy usage by blunting catecholamine surges and reduce circulating free fatty acids via inhibition of lipolysis, protecting against ventricular fibrillation and sudden cardiac death. Beta blockers also produce a shift of myocardial energy usage from fatty acid oxidation towards glucose, which further improves myocardial oxygenation and energy efficiency, and they also reduce blood pressure via their anti-renin/angiotensin properties [23].

There was widespread initial enthusiasm for the perioperative use of beta-blockers following the publication of a number of relatively small but very compelling studies, although there have since been some concerns over the integrity of one of the authors. More recent and larger trials with slightly different design, inclusion criteria and also type and dose of beta blockers used have dampened this. Among them, the largest multicentre randomized controlled trial is the POISE study [24]. In POISE, extended-release metoprolol significantly reduced myocardial infarction $(4.2 \%$ vs $5.7 \% ; \mathrm{p}=.0017)$ but increased stroke ( $1.0 \%$ vs $0.5 \%$; $\mathrm{p}=.0053)$, thereby resulting in a higher overall mortality $(3.1 \%$ vs $2.3 \%$; $\mathrm{p}=.0317$ ). Some limitations of POISE were that only the outcomes of acute perioperative beta blockade were 
studied, the effect of withdrawal of beta blockers was overlooked and the same dose was used in all patients with no titration to effect.

A number of other studies have now shown a myocardial benefit from perioperative beta blockade at the cost of other harmful outcomes. The general consensus is that high risk patients will benefit from beta blockers, but it is apparent that a routine fixed regimen of therapy perioperatively may be harmful in low/intermediate risk groups. The variable response among patients may be partially explained by genetic polymorphism and, therefore, it seems prudent that individualised therapy should be implemented when that becomes possible. The type of beta blocker used might also have contributed to different study outcomes. Although trials clearly demonstrate cardioprotective effects, some evidence suggests that those that are highly $\beta 1$ selective show better results than those that are moderately $\beta 1$ selective. This might explain why bisoprolol (highly $\beta 1$ selective) has been associated with better results, and metoprolol and atenolol (moderately $\beta 1$ selective) have been associated with mixed results in clinical trials. In one large trial with patients receiving perioperative beta blockers, longer acting agents (e.g. atenolol) gave greater cardioprotection than short-acting agents (e.g. metoprolol) [25]. Currently, several guidelines recommend continuation of beta blocker therapy in chronic treatment (e.g. the AHA have this as a class I guideline indication [8]). The recommendation to use beta blockers in patients undergoing vascular surgery who are at high cardiac risk (e.g. those with evidence of coronary artery disease, cardiac ischaemia on preoperative testing) shifted from a class I to a class IIa level of evidence and there are similar guidelines from the European Society of Cardiology (ESC) [26]. High-, and possibly intermediate-, risk individuals are likely to benefit from beta blockers but careful titration of heart rate to 60 and $80 \mathrm{bpm}$ and blood pressure response is suggested [8]. Therapy should ideally start as soon as possible before surgery ( 30 days to 1 week) but can still be considered acutely. As yet, there are no guidelines on postoperative duration of therapy, or whether it should be lifelong.

\section{Statins}

Statins are a class of drugs used to lower cholesterol levels by inhibiting the enzyme HMG-CoA reductase, which plays a central role in the production of cholesterol in the liver. Although hypercholesterolaemia is a risk factor for ischaemic heart disease, recent data suggest that the cardioprotective effect of statins is also related to their pleiotropic effects beyond low density lipoprotein (LDL) lowering [27]. These include increased endothelial nitric oxide synthetase with improved endothelial function, improved thrombogenic profile, anti-inflammation, and inhibition of artherosclerosis. They have a very good safety profile. Rhabdomyolysis, the most serious complication, is extremely rare and about $2 \%$ of patients develop raised transaminases, which are reversible on cessation of therapy.

A recent systematic review [28] and meta-analysis found that perioperative statin treatment in statin-naive patients reduces atrial fibrillation, myocardial infarction, and duration of hospital stay. Several small prospective studies introducing statins prior to high-risk vascular surgery have shown a reduction in myocardial infarction, stroke and death, irrespective of initial serum cholesterol level $[29,30]$. There is also an association with a reduced incidence of contrast-induced nephropathy [31]. In view of the relative safety and pharmacoeconomic benefits, it has even been suggested that perioperative statin therapy for patients with cardiac disease undergoing non-cardiac surgery may be the most cost-effective use yet discovered [32].

\section{Coronary artery interventions}

Two randomized controlled trials have found absolutely no postoperative or long-term benefit from percutaneous coronary intervention in high-risk patients undergoing major vascular surgery compared with the best medical treatment alone. This reflects the inherent complications of such procedures and the fact that patients having coronary stents are at high risk of in-stent thrombosis with high mortality, especially if antiplatelet agents are stopped perioperatively. As for coronary artery bypass surgery, it is suggested that only those who might benefit from coronary artery bypass surgery independent of their need for surgery should be considered.

\section{Myocardial conditioning}

Preconditioning is a form of myocardial protection that delays the trespass of the ischaemic threshold by lowering metabolic demand, and then secondarily mitigating the adverse consequences of reperfusion as the blood supply is restored. In 1986, Murry and colleagues observed that intermittent ischaemia intentionally applied to the myocardium actually improved its ability to withstand subsequent ischaemia of greater magnitude [33]. This adaptive phenomenon was termed ischaemic preconditioning, but the mechanical nature of its application rendered it cumbersome and time consuming, and, consequently, it was not adopted as routine practice. However, the potential clinical implications of this fascinating innate cardioprotective observation inspired many researchers to examine the underlying molecular mechanisms. It became apparent that certain ligand-receptor interactions can activate similar pathways and replicate the preconditioning response. Interestingly, many of these preconditioning pharmacomimetics 
include drugs that are already in perioperative use such as volatile anaesthetics and opioids. It was later observed that mechanical ischaemia at the time of reperfusion could also produce protection (postconditioning) and this, also, could be induced by the same drugs (pharmacologic postconditioning). Przyklenk and others observed that an ischaemic stimulus applied to the circumflex coronary artery protected the area of tissue supplied by the left anterior descending coronary artery and, from this observation, spawned the concept of remote preconditioning [34]. The application of the protective stimulus to an organ remote to the heart became an attractive proposition as it avoids many of the limitations of direct ischaemic preconditioning. Although details of mechanisms of cardioprotection continue to accumulate in the laboratory, translation to the clinical setting has been disappointing. Part of the reason is that diseased and senescent myocardium does not behave like the normal myocardium of animals in the laboratory. In addition, patients with coronary artery disease may already be preconditioned with ischaemia such that preconditioning drugs confer little additional benefit, and most clinical studies have been in patients undergoing cardiac surgery rather than those with cardiac disease undergoing non-cardiac surgery.

\section{Anaesthetic interventions}

Certain volatile anaesthetic agents mimic some of the biological effects of ischaemic preconditioning with signal transduction pathways very similar to those responsible for ischaemic preconditioning. It is hypothesized that volatile anaesthetics stimulate a trigger that initiates a cascade of events leading to activation of an end-effector that is responsible for resistance to injury. Adenosine type 1 (A1) receptors, protein kinase C (PKC), inhibitory guanine nucleotide binding (Gi) proteins, reactive oxygen species, and mitochondrial and sarcolemmal ATP-sensitive potassium channels have all been implicated. There also appear to be important roles for prosurvival kinases such as phosphoinositide 3-kinase (PI3K)/Akt40 and the transcription factor HIF-1 [35]. Volatile anaesthetics also produce coronary vasodilation by activating ATP-sensitive potassium channels or by affecting intracellular $\mathrm{Ca} 2+$ homeostasis in vascular smooth muscle. For example, sevoflurane can increase collateral blood flow to ischaemic myocardium and improve the functional recovery of coronary vascular reactivity and nitric oxide release in isolated hearts after global ischaemia [36]. Volatile anaesthetics may also attenuate apoptosis after ischaemia/reperfusion and shift the myocardium into an "anti-apoptotic" state by modulation of proteins of the BCL-2 family. Consequently, the use of volatile agents, particularly sevoflurane, as a primary anaesthetic agent has undergone a resurgence in popularity despite previous concerns over their negative inotropic effects.

Opioid receptor activation can also confer cardiac protection, in particular the delta and kappa receptor subtypes. Intravenous morphine mimics the effects of ischaemic preconditioning, albeit at high doses [37]. The requirement for activation of delta and kappa receptors by morphine may explain the relatively high doses necessary to trigger cardioprotection (morphine being predominantly a mu agonist). Such high morphine doses would cause prolonged respiratory depression and sedation and would be impractical for large scale clinical use, so the advent of remifentanil, with its favourable pharmacokinetic profile, enabled clinical trials of opioid cardioprotection to be conducted. A meta-analysis of remifentanil use in cardiac surgery of 1473 patients showed that it is associated with a reduction in cardiac troponin release, time of mechanical ventilation, and length of hospital stay [38]. Remifentanil also attenuates tachycardia, which improves the myocardial oxygen supply/demand ratio in a similar way to beta blockers.

Reactive oxygen species have been implicated in ischaemia/reperfusion injury. Propofol appears to be a powerful antioxidant with effects similar to alphatocopherol, which protects against cardiac ischaemia/ reperfusion injury mainly via enhancement of endogenous antioxidant capacity in the myocardium [39]. This mechanism is totally different from volatile anaesthetic preconditioning. Propofol reduced reactive oxygen species-induced lipid peroxidation and attenuated ischaemia/reperfusion injury in isolated rat hearts in a dose-dependent manner and can prevent hydrogen peroxide-mediated exacerbation of tumor necrosis factor (TNF)- $\alpha$ cellular toxicity [40], which might be a mechanism whereby it attenuates hydrogen peroxideinduced cardiac dysfunction. More recently, it has also been shown that propofol post-conditioning confers protection against myocardial as well as cerebral ischaemia/reperfusion injury, probably through maintaining the activity of the prosurvival PI3K/Akt pathway $[40,41]$. Currently, however, there is not enough evidence to definitively support the use of any particular anaesthetic regime for cardioprotection in patients.

\section{Nitrous oxide}

The administration of nitrous oxide was associated with increased long-term risk of myocardial infarction $(1.3 \%$ vs $0.7 \%$; adjusted $\mathrm{P}=0.19)$, but not of death or stroke in patients enrolled in the ENIGMA-1 trial [42]. Nitrous oxide inhibits methionine synthetase, which mediates an increase in homocysteine, which is an independent risk factor for coronary artery and cerebral vascular disease. 
Increases in homocysteine have been found to cause endothelial dysfunction, impair myocardial substrate utilization, and enhance platelet aggregation. In a substudy of ENIGMA-I, 394 unselected patients had homocysteine measured preoperatively and on the first postoperative day, which showed that a deficiency of folate or B vitamins increased the incidence of hyperhomocysteinemia four-fold. Hyperhomocysteinemia was associated with a doubling of the rate of major complications. However, the longer-term results of the original ENIGMA-I trial found that patients exposed to nitrous oxide had an increased incidence of myocardial infarction, in a mean follow-up period of 3.5 years after a nitrous oxide-based general anaesthetic [43]. Consequently, the routine use of nitrous oxide in patients undergoing major surgery should be questioned.

\section{Dexmedetomidine}

Dexmedetomidine is a highly selective alpha-2 agonist that provides sedation and analgesia without respiratory depression. It activates pro-survival kinases and attenuates ischaemia and hypoxic injury, including cardioprotection [44], neuroprotection [45], and renoprotection [46]. Concurrent infusion during surgery reduces anaesthetic consumption by $20-50 \%$ [47] and produces a moderate decrease in heart rate and blood pressure that may be advantageous in ischaemic heart disease by improving oxygen supply/demand balance [48].

\section{Thoracic epidural analgesia}

Good pain control is an extremely important facet of the anaesthetic technique, as it decreases stress hormone production, sympathetic tone and myocardial oxygen consumption. Thoracic epidural analgesia had been thought to provide cardioprotective effects in patients undergoing noncardiac surgery in several small studies but this has not been borne out in meta-analysis [49] or in the MASTER trial [50], where the only benefit was a reduction in postoperative respiratory complications.

\section{Blood glucose and blood pressure interventions}

Diabetes mellitus is strongly associated with cardiovascular disease, autonomic neuropathy and resistance to preconditioning. Drugs like the glucose-lowering drug glibenclamide also inhibit preconditioning. Interestingly, however, a recent retrospective cohort study of 32,834 patients with known cardiac disease, of whom $28 \%$ had diabetes, found similar all-cause 30-day mortality after noncardiac surgery [42]. None of the glucose-lowering drug classes were associated with perioperative mortality in elderly cardiac patients but use of angiotensin-converting-enzyme (ACE) inhibitor or angiotensin receptor blockers, beta-blockers, or statins in the 100 days before surgery were associated with lower 30-day mortality [51]. When the vogue for aggressive use of insulin for tight perioperative glucose control based on initial observational studies in the intensive care unit setting was later investigated in proper randomised trials, it was found to actually cause higher mortality. Although it is prudent to avoid hyperglycaemia, such aggressive treatment is no longer recommended [52].

As with aspirin and statins, there is strong evidence that long-term ACE inhibition yields significant cardiovascular protective effects. Traditionally it was common to discontinue ACE inhibitors preoperatively because of an association with intraoperative hypotension. However, a recent large prospective study investigating postoperative cardiovascular outcomes in patients with different patterns of perioperative ACE inhibitor/angiotensin receptor blockers use found that, although there was no change in 30-day in-hospital mortality, withdrawal of an ACE inhibitor was associated with an increased number of cardiovascular events, mainly congestive heart failure and postoperative myocardial infarction [53]. Such high-level evidence suggests that ACE inhibitor therapy should be continued if possible, particularly considering that blood pressure changes during surgery are easily attenuated with vasopressors such as phenylephrine.

\section{Conclusion}

There is no "magic bullet" for the prevention of perioperative cardiovascular morbidity and mortality. However, an appropriate strategy is to identify those at risk as early as possible and intervene, if needed, with consideration of the urgency and nature of surgery. The risk and benefit of surgery should also be seriously considered in the context of less invasive alternatives if possible (e.g. endovascular repair for aortic aneurysectomy). Current evidence strongly supports the use of aspirin and statins. Beta blockade may be beneficial in higher-risk groups but needs to be titrated to effect. Chronic cardiovascular therapy including ACE inhibitor/ angiotensin receptor blockers should be maintained and there is no need for tight blood glucose control in diabetes. While certain volatile anaesthetics and opioids show promising effects in mitigating ischaemia/reperfusion injury, large prospective randomized trials are still needed to determine their clinical potential.

\section{Disclosures}

The authors declare that they have no disclosures.

\section{Abbreviations}

ACE, angiotensin converting enzyme; AHA, American Heart Association; DVT, deep vein thrombosis; LDL, 
low density lipoprotein; NSAIDs, non-steroidal antiinflammatory drugs; $\mathrm{PI} 3 \mathrm{~K}$, phosphoinositide 3-kinase; $\mathrm{PKC}$, protein kinase $\mathrm{C}$; $\mathrm{TNF}$, tumor necrosis factor.

\section{References}

I. Bainbridge D, Martin J, Arango M, Cheng D: Perioperative and anaesthetic-related mortality in developed and developing countries: a systematic review and meta-analysis. Lancet 2012, 380: 1075-8I.

\section{FlOOOPrime}

2. Merry AF, Webster CS: Has anesthesia care become safer and is anesthesia-related mortality decreasing? FI000 Med Rep 2009, I.

\section{FlOOOPrime}

3. Roger VL, Go AS, Lloyd-Jones DM, Benjamin EJ, Berry JD, Borden WB, Bravata DM, Dai S, Ford ES, Fox CS, Fullerton HJ, Gillespie C, Hailpern SM, Heit JA, Howard VJ, Kissela BM, Kittner SJ, Lackland DT, Lichtman JH, Lisabeth LD, Makuc DM, Marcus GM, Marelli A, Matchar DB, Moy CS, Mozaffarian D, Mussolino ME, Nichol G, Paynter NP, Soliman EZ, et al.: Executive summary: heart disease and stroke statistics-20I2 update: a report from the American Heart Association. Circulation 2012, I25: 188-97.

\section{FlOOOPrime RECOMMENDED}

4. Abrams J: Clinical practice. Chronic stable angina. $N$ Engl J Med 2005, 352:2524-33.

5. Lucreziotti S, Carletti F, Santaguida G, Fiorentini C: Myocardial infarction in major noncardiac surgery: Epidemiology, pathophysiology and prevention. Heart Int 2006, 2:82.

\section{FlOOOPRime}

6. Fleisher LA, Beckman JA, Brown KA, Calkins H, Chaikof E, Fleischmann KE, Freeman WK, Froehlich JB, Kasper EK, Kersten JR, Riegel B, Robb JF, Smith SC, Jacobs AK, Adams CD, Anderson JL, Antman EM, Buller CE, Creager MA, Ettinger SM, Faxon DP, Fuster V, Halperin JL, Hiratzka LF, Hunt SA, Lytle BW, Nishimura R, Ornato JP, Page RL, Tarkington LG, et al.: ACC/AHA 2007 guidelines on perioperative cardiovascular evaluation and care for noncardiac surgery: a report of the American College of Cardiology/American Heart Association Task Force on Practice Guidelines (Writing Committee to Revise the 2002 Guidelines on Perioperative Cardiovascular Evaluation for Noncardiac Surgery): developed in collaboration with the American Society of Echocardiography, American Society of Nuclear Cardiology, Heart Rhythm Society, Society of Cardiovascular Anesthesiologists, Society for Cardiovascular Angiography and Interventions, Society for Vascular Medicine and Biology, and Society for Vascular Surgery. Circulation 2007, I 16:e4|8-99.

7. Lee TH, Marcantonio ER, Mangione CM, Thomas EJ, Polanczyk CA, Cook EF, Sugarbaker DJ, Donaldson MC, Poss R, Ho KK, Ludwig LE, Pedan A, Goldman L: Derivation and prospective validation of a simple index for prediction of cardiac risk of major noncardiac surgery. Circulation 1999, 100:1043-9.

\section{FlOOOPrime \\ RECOMMENDED}

8. Fleisher LA, Beckman JA, Brown KA, Calkins H, Chaikof EL, Fleischmann KE, Freeman WK, Froehlich JB, Kasper EK, Kersten JR, Riegel B, Robb JF: 2009 ACCF/AHA focused update on perioperative beta blockade incorporated into the $\mathrm{ACC} /$ AHA 2007 guidelines on perioperative cardiovascular evaluation and care for noncardiac surgery. I Am Coll Cardiol 2009, 54:el3-ell8.

FIOOOPrime

9. Chassot P, Delabays A, Spahn DR: Perioperative antiplatelet therapy: the case for continuing therapy in patients at risk of myocardial infarction. Br J Anaesth 2007, 99:316-28.

\section{FlOOOPrime}

\section{RECOMMENDED}

10. Ozao-Choy J, Tammaro Y, Fradis M, Weber K, Divino CM: Clopidogrel and bleeding after general surgery procedures. Am Surg 2008, 74:72I-5.

II. Vane JR, Botting RM: The mechanism of action of aspirin. Thromb Res 2003, I 10:255-8.

\section{FlOOOPrime}

RECOMMENDED

12. Hennekens $\mathrm{CH}$ : Aspirin in the treatment and prevention of cardiovascular disease: current perspectives and future directions. Curr Atheroscler Rep 2007, 9:409-16.

\section{FlOOOPrime
RECOMMENDED}

13. Burger W, Chemnitius J, Kneissl GD, Rücker G: Low-dose aspirin for secondary cardiovascular prevention - cardiovascular risks after its perioperative withdrawal versus bleeding risks with its continuation - review and meta-analysis. J Intern Med 2005, 257:399-4I4.

FlOOOPrime

14. Gerstein NS, Schulman PM, Gerstein WH, Petersen TR, Tawil I: Should more patients continue aspirin therapy perioperatively?: clinical impact of aspirin withdrawal syndrome. Ann Surg 2012, 255:8II-9.

\section{FlOOOPrime}

15. Kałuza GL, Joseph J, Lee JR, Raizner ME, Raizner AE: Catastrophic outcomes of noncardiac surgery soon after coronary stenting. J Am Coll Cardiol 2000, 35: I288-94.

\section{FlOOOPrime
RECOMMENDED}

16. Nuttall GA, Brown MJ, Stombaugh JW, Michon PB, Hathaway MF, Lindeen KC, Hanson AC, Schroeder DR, Oliver WC, Holmes DR, Rihal CS: Time and cardiac risk of surgery after bare-metal stent percutaneous coronary intervention. Anesthesiology 2008, 109:588-95.

\section{FlOOOPrime
RECOMMENDED}

17. Schouten O, van Domburg RT, Bax Il, de Jaegere PJ, Dunkelgrun M, Feringa HHH, Hoeks SE, Poldermans D: Noncardiac surgery after coronary stenting: early surgery and interruption of antiplatelet therapy are associated with an increase in major adverse cardiac events. J Am Coll Cardiol 2007, 49:122-4.

FlOOOPrime

18. Rhee SJ, Yun KH, Lee SR, Chae J, Nam C, Jun D, Jeong J: Drugeluting stent thrombosis during perioperative period. Int Heart | 2008, 49: 135-42.

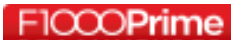
RECOMMENDED

19. Rabbitts JA, Nuttall GA, Brown MJ, Hanson AC, Oliver WC, Holmes DR, Rihal CS: Cardiac risk of noncardiac surgery after 
percutaneous coronary intervention with drug-eluting stents. Anesthesiology 2008, 109:596-604.

\section{FIOOOPrime

RECOMMENDED

20. McGettigan P, Henry D: Cardiovascular risk and inhibition of cyclooxygenase: a systematic review of the observational studies of selective and nonselective inhibitors of cyclooxygenase 2. JAMA 2006, 296:1633-44.

\section{FlOOPrime}

\section{RECOMMENDED}

21. Nussmeier NA, Whelton AA, Brown MT, Langford RM, Hoeft A Parlow JL, Boyce SW, Verburg KM: Complications of the COX-2 inhibitors parecoxib and valdecoxib after cardiac surgery. N Engl J Med 2005, 352:|08|-9|.

\section{FlOOOPrime}

22. Prabhu SD, Chandrasekar B, Murray DR, Freeman GL: betaadrenergic blockade in developing heart failure: effects on myocardial inflammatory cytokines, nitric oxide, and remodeling. Circulation 2000, 10 1:2103-9.

\section{FlOOOPrime} RECOMMENDED

23. Yeager MP, Fillinger MP, Hettleman BD, Hartman GS: Perioperative beta-blockade and late cardiac outcomes: a complementary hypothesis. J Cardiothorac Vasc Anesth 2005, 19:237-4I.

\section{FlOOOPrime} RECOMMENDED

24. Devereaux PJ, Yang H, Yusuf S, Guyatt G, Leslie K, Villar JC, Xavier D, Chrolavicius S, Greenspan L, Pogue J, Pais P, Liu L, Xu S, Málaga G, Avezum A, Chan M, Montori VM, Jacka M, Choi P: Effects of extended-release metoprolol succinate in patients undergoing non-cardiac surgery (POISE trial): a randomised controlled trial. Lancet 2008, 37|:|839-47.

\section{FlOOOPrime \\ RECOMMENDED}

25. Redelmeier D, Scales D, Kopp A: Beta blockers for elective surgery in elderly patients: population based, retrospective cohort study. BMJ 2005, 331:932.

\section{FlOOOPrime \\ RECOMMENDED}

26. Poldermans D, Bax J], Boersma E, de Hert S, Eeckhout E, Fowkes G, Gorenek B, Hennerici MG, lung B, Kelm M, Kjeldsen KP, Kristensen SD, Lopez-Sendon J, Pelosi P, Philippe F, Pierard L, Ponikowski P, Schmid J, Sellevold OFM, Sicari R, van den Berghe G, Vermassen F: Guidelines for pre-operative cardiac risk assessment and perioperative cardiac management in non-cardiac surgery. Eur Heart J 2009, 30:2769-812

\section{FlOOOPrime}

27. Pedersen TR: Pleiotropic effects of statins: evidence against benefits beyond LDL-cholesterol lowering. Am I Cardiovasc Drugs 2010, I0(Suppl I):10-7.

\section{FlOOOPrime \\ RECOMMENDED}

28. Beri A, Sural N, Mahajan SB: Non-atheroprotective effects of statins: a systematic review. Am J Cardiovasc Drugs 2009, 9:36 I-70.

\section{FlOOOPrime RECOMMENDED}

29. Durazzo AES, Machado FS, lkeoka DT, de Bernoche C, Monachini MC, Puech-Leão $\mathrm{P}$, Caramelli B: Reduction in cardiovascular events after vascular surgery with atorvastatin: a randomized trial. J Vasc Surg 2004, 39:967-75; discussion 975-6.
30. Ward RP, Leeper NJ, Kirkpatrick JN, Lang RM, Sorrentino MJ, Williams KA: The effect of preoperative statin therapy on cardiovascular outcomes in patients undergoing infrainguinal vascular surgery. Int J Cardiol 2005, I 04:264-8.

\section{FlOOOPrime
RECOMMENDED}

31. Khanal S, Attallah N, Smith DE, Kline-Rogers E, Share D, O'Donnell MJ, Moscucci M: Statin therapy reduces contrastinduced nephropathy: an analysis of contemporary percutaneous interventions. Am J Med 2005, I I 8:843-9.

\section{FlOOOPrime}

RECOMMENDED

32. Biccard BM, Sear JW, Foëx P: The pharmaco-economics of perioperative statin therapy. Anaesthesia 2005, 60:1059-63.

\section{FlOOOPrime
RECOMMENDED}

33. Murry CE, Jennings RB, Reimer KA: Preconditioning with ischemia: a delay of lethal cell injury in ischemic myocardium. Circulation 1986, 74: | I24-36.

\section{FlOOOPrime}

34. Przyklenk K, Bauer B, Ovize M, Kloner RA, Whittaker P: Regional ischemic 'preconditioning' protects remote virgin myocardium from subsequent sustained coronary occlusion. Circulation 1993, 87:893-9.

\section{FlOOOPrime}

\section{RECOMMENDED}

35. Riess ML, Stowe DF, Warltier DC: Cardiac pharmacological preconditioning with volatile anesthetics: from bench to bedside? Am J Physiol Heart Circ Physiol 2004, 286:HI603-7.

36. Frädorf J, Huhn R, Weber NC, Ebel D, Wingert N, Preckel B, Toma O, Schlack W, Hollmann MW: Sevoflurane-induced preconditioning: impact of protocol and aprotinin administration on infarct size and endothelial nitric-oxide synthase phosphorylation in the rat heart in vivo. Anesthesiology 2010, I I 3:1289-98.

\section{FlOOOPrime
RECOMMENDED}

37. Schultz JE, Hsu AK, Gross GJ: Morphine mimics the cardioprotective effect of ischemic preconditioning via a glibenclamidesensitive mechanism in the rat heart. Circ Res 1996, 78: 1 100-4.

\section{FlOOOPrime
RECOMMENDED}

38. Greco M, Landoni G, Biondi-Zoccai G, Cabrini L, Ruggeri L, Pasculli N, Giacchi V, Sayeg J, Greco T, Zangrillo A: Remifentanil in cardiac surgery: a meta-analysis of randomized controlled trials. J Cardiothorac Vasc Anesth 20I2, 26: I 10-6.

\section{FlOOOPrime} RECOMMENDED

39. Xia Z, Huang Z, Ansley DM: Large-dose propofol during cardiopulmonary bypass decreases biochemical markers of myocardial injury in coronary surgery patients: a comparison with isoflurane. Anesth Analg 2006, 103:527-32.

\section{FlOOOPRime}

40. Huang Z, Zhong X, Irwin MG, Ji S, Wong GT, Liu Y, Xia Z, Finegan BA, Xia Z: Synergy of isoflurane preconditioning and propofol postconditioning reduces myocardial reperfusion injury in patients. Clin Sci 201 I, I 21:57-69.

4I. Wang H, Luo M, Li C, Wang G: Propofol post-conditioning induced long-term neuroprotection and reduced internalization of AMPAR GluR2 subunit in a rat model of focal cerebral ischemia/reperfusion. J Neurochem 2011, I19:210-9.

42. Myles PS, Leslie K, Chan MTV, Forbes A, Paech MJ, Peyton P, Silbert BS, Pascoe E: Avoidance of nitrous oxide for patients undergoing 
major surgery: a randomized controlled trial. Anesthesiology 2007, 107:22I-31.

\section{FlOOOPrime}

43. Leslie K, Myles PS, Chan MTV, Forbes A, Paech MJ, Peyton P, Silbert BS, Williamson E: Nitrous oxide and long-term morbidity and mortality in the ENIGMA trial. Anesth Analg 20I I, I I 2:387-93.

\section{FlOOOPrime}

\section{RECOMMENDED}

44. Ibacache M, Sanchez G, Pedrozo Z, Galvez F, Humeres C, Echevarria G, Duaso J, Hassi M, Garcia L, Díaz-Araya G, Lavandero S: Dexmedetomidine preconditioning activates pro-survival kinases and attenuates regional ischemia/reperfusion injury in rat heart. Biochim Biophys Acta 20I2, 1822:537-45.

45. Zhu Y, Wang C, Chen L, Qian L, Ma L, Yu J, Zhu M, Wen C, Yu L, Yan M: Both PI3K/Akt and ERKI/2 pathways participate in the protection by dexmedetomidine against transient focal cerebral ischemia/reperfusion injury in rats. Brain Res 2013, I494:I-8.

46. Gu J, Sun P, Zhao H, Watts HR, Sanders RD, Terrando N, Xia P, Maze M, $M a$ D: Dexmedetomidine provides renoprotection against ischemia-reperfusion injury in mice. Crit Care 20II, I5:RI53.

47. Aantaa R, Jaakola ML, Kallio A, Kanto J: Reduction of the minimum alveolar concentration of isoflurane by dexmedetomidine. Anesthesiology 1997, 86: 1055-60.

48. Biccard BM, Goga S, de Beurs J: Dexmedetomidine and cardiac protection for non-cardiac surgery: a meta-analysis of randomised controlled trials. Anaesthesia 2008, 63:4-I4.

49. Gauss A, Jahn SK, Eberhart LHJ, Stahl W, Rockemann M, Georgieff M, Wagner F, Meierhenrich R: Kardioprotektion durch thorakale Periduralanästhesie? Metaanalyse. Anaesthesist 201 I, 60:950-62.

FlOOOPrime
RECOMMENDED

50. Rigg JRA, Jamrozik K, Myles PS, Silbert BS, Peyton PJ, Parsons RW, Collins KS: Epidural anaesthesia and analgesia and outcome of major surgery: a randomised trial. Lancet 2002, 359: 1276-82.

FlOOOPrime RECOMMENDED

5I. Hanninen M, McAlister FA, Bakal JA, van Diepen S, Ezekowitz JA: Neither Diabetes nor Glucose-Lowering Drugs Are Associated With Mortality After Noncardiac Surgery in Patients With Coronary Artery Disease or Heart Failure. Can J Cardiol 2012.

FlOOOPrime

RECOMMENDED

52. Inzucchi SE, Siegel MD: Glucose control in the ICU-how tight is too tight? N Engl J Med 2009, 360: 1346-9.

FIOOOPrime
RECOMMENDED

53. Drenger B, Fontes ML, Miao Y, Mathew JP, Gozal $Y$, Aronson S, Dietzel C, Mangano DT: Patterns of use of perioperative angiotensin-converting enzyme inhibitors in coronary artery bypass graft surgery with cardiopulmonary bypass: effects on in-hospital morbidity and mortality. Circulation 2012, 126:26I-9.

F100OPrime 